\title{
Aggression in rats as a function of frustrative nonreward in a straight alley'
}

\author{
GORDON G. GALLUP, JR. \\ WASHINGTON STATE UNIVERSITY
}

\begin{abstract}
Abstraet
After being trained in a straight alley for $100 \%$ food reward, 12 female albino rats were tested in a double straight alley in pairs on a random $50 \%$ schedule of reinforcement. At the end of a 30-sec. interval in the goal box, the Ss were allowed free access to one another for an additional 60 sec., during which time, measures of aggression were taken according to the Klein-Hall scale of aggressiveness. Significantly more overt aggression occurred following nonreinforced trials than after reinforced trials. With a few reservations, the results are interpreted as lending support to the notion of frustrative nonreward in partial reinforcement situations.
\end{abstract}

\section{Introduetion}

The use of frustration as an interpretation of or explanation for the effects of partial reinforcement has, within the last 15 years, become quite popular. Stemming mainly from the work of Amsel \& Roussel (1952) an abundance of data has been gathered in support of such a notion (e.g. Amsel, 1958; Amsel, 1962). To date, measures of running speed in different segments of an alley (e.g. Goodrich, 1959), and indices of resistance to extinction (e.g. Weinstock, 1954) constitute the vast majority of dependent variables from which the so-called frustration effect has been inferred.

At the initial suggestion of Dollard et al (1939) numerous investigators have sought to demonstrate a relationship between the administration of frustration operations and subsequent indices of aggression, with the result that considerable data have been gathered in support of the "frustration-aggression" hypothesis (e.g. Buss, 1961). However, an attempt to relate the effect of frustrative nonreward or partial reinforcement to aggression, in terms of the traditional straight alley situation, has yet to be made.

\section{Subjects and Apparatus}

Twelve 150 day old experimentally naive female albino rats, housed in cages of three, from the colony maintained by the Washington State University Psychology Department, served as Ss.

The apparatus consisted essentially of two parallel 55-in runways separated by a piece of plywood running lengthwise between both alleys. Each alley was 4 in wide, with a 9-in start box, and a 10-in goal box. In addition to the standard start box and goal box guillotine doors, each of the adjacent goal boxes were separated by another guillotine door which could be manipulated by the $\mathrm{E}$ so as to allow Ss access to one another under the appropriate conditions. A plywood floor was used and the entire apparatus was painted flat black.

\section{Procedure}

Following 12 days of 23-hr. food deprivation, during which time each $\mathrm{S}$ was handled for approximately $3 \mathrm{~min}$. per day, preliminary training was begun and consisted of two days of $10-\min$. free exploration periods in the alley. Subsequent to familiarization, 40 training trials were given over a period of 12 consecutive days. Training consisted of running two Ss, one in each alley, through the apparatus for five $97-\mathrm{mg}$ food pellets in the goal box on a continuous or $100 \%$ reinforcement schedule. Upon entering the goal box each $\mathrm{S}$ was allowed $30 \mathrm{sec}$. to consume the food reward before being removed. During training both alleys were utilized simultaneously, but the guillotine door separating the two goal boxes was always left closed. Each $\mathrm{S}$ received one training trial on Days 1 and 2, and two trials on Day 3. Following this, four trials were administered each day with an interval of approximately $15 \mathrm{~min}$. and at an average of $221 / 2 \mathrm{hr}$. of food deprivation.

Test trials were essentially the same as training trials, except that all Ss were switched to a random $50 \%$ schedule of reinforcement. At the end of the initial 30 -sec. interval in the goal box the guillotine door separating the two goal boxes was raised and the pair was allowed free access to one another for an additional 60 sec., during which time, measures of aggression were taken according to the Klein-Hall seven point scale of aggressiveness between rats (Hall \& Klein, 1942). Twenty-four test trials were run over a period of six consecutive days (four trials per day), and Ss were randomly assigned to different pairs on each trial. The intertrial interval during testing was approximately $20 \mathrm{~min}$. and Ss were run at an average of $221 / 4 \mathrm{hr}$. of food deprivation. During testing it was necessary to put glass over the goal boxes in order to retain the Ss in the apparatus for the required length of time.

\section{Results}

The randomly selected pairs were treated as replications and a three-dimensional analysis of variance was computed. The difference in terms of overtaggression, as measured by the Klein-Hall scale on reinforced vs. nonreinforced trials, proved to be significant well beyond the .001 level $(\mathrm{F}=127.09, \mathrm{df}=1 / 5, \mathrm{p}<.001)$; with the mean aggression scores over all pairs being 6.83 for nonreinforced trials and 1.67 for reinforced trials. Since the trials effect and all of the various interactions were nonsignificant, multiple comparisons were not made. 


\section{Diseussion}

In studies using frustrative nonreward, frustration in most instances has been identified with faster running speeds in a straight alley and/or greater resistance to extinction. The present study dealt with the effect of intermittent reinforcement on measures of aggression between female albino rats, in an attempt to question further the existence of frustration in situations involving partial reinforcement. In these situations the major source of frustration is identified with nonreward under conditions where the $\mathrm{S}$ has learned to expect reward.

The incidence of aggressive behavior within random pairs of rats was significantly higher on nonreinforced trials than on reinforced trials. Thus, these results would seem to lend general support to a frustration interpretation of the active motivational properties of nonreward, given the assumption that aggression is a fairly reliable index of frustration under these conditions. It is important to note, however, that in most instances the amount of aggression displayed, while consistently different between reinforced and nonreinforced trials, was not exceedingly large; e.g. in only a few cases was there actually any blood shed.

In addition, it shoud be pointed out that these findings are not entirely in accord with the predictions of frustration theory as formulated by Amsel (1958) and Spence (1960). The Amsel-Spence interpretation would seem to predict a considerable amount of frustration on reinforced trials, due to the stipulation that hypothetical internal cues of frustration on nonreinforced trials are seen as being conditioned to goal box cues,

\section{Reply}

It is certainly "fair to ask" how great a percentage of the variance in instrumental performance in the postshift phase is accounted for by the experimental treatment. On post-shift trial 36, after 6 days of equal reinforcement for Groups 400-20 and 20-3, 10\% of the variance in these two groups was attributable to the original reinforcement. It is not fair, however, to compare this index with the amount of variance "accounted for" by the correlation between instrumental and consummatory performance because the implications of the two percentages are logically quite different. In the case of the experimental treatment it is proper to speak of "accounting for" and to mean thereby a causative relationship but in the case of a correlation between two dependent variables it is proper to use the phrase "variance in common" which has no confusing causative connotations. (We should not have continued the misleading use of "account for" in this context.)

The intriguing finding in the reported study was that a group shifted in incentive from 400 licks of a $20 \%$ sucrose solution to 20 licks of a $3 \%$ solution (Group 400-20), showed a remarkably slow change in instrumental performance. There are a number of potential explanations of this finding, which has been replicated such that fractional anticipatory frustration should be elicited on both reinforced and nonreinforced trials. Yet, within the context of the present study, little or no aggressive behavior was observed on reward trials; although, a slight increase was observed over trials. That condition frustration may in part be neutralized or in some way counteracted by the presence of food in the goal box on reinforced trials exists as a possible interpretation of these results.

\section{References}

Amsel, A. The role of frustrative nonreward in noncontinuous reward situations. Psychol. Bull., 1958, 55, 102-119.

Amsel, A. Frustrative nonreward in partial reinforcement and discrimination learning: Some recent history and a theoretical extention. Psychol. Rev., 1962, 69, 306-328.

Amsel, A., \& Roussel, J. Motivational properties of frustration: I. Effect on a running response of the addition of frustration to the motivational complex. J. exp. Psychol., 1952, 43, 363-368.

Buss, A. H. The psychology of aggression. New York: Wiley, 1961.

Dollard, J., Dobb, L. W., Miller, N. E., Mowrer, O. H., \& Sears, R. R. Frustration and aggression. New Haven: Yale University Press, 1939.

Goodrich, K. P. Performance in different segments of an instrumental response chain as a function of reinforcement schedule. J. exp. Psychol., 1959, 57, 57-64.

Hall, C. S., \& Klein, S. J. Individual differences in aggressiveness in rats. J. comp. Psychol., 1942, 33, 371-383.

Spence, K. W. Behavior theory and learning. Englewood Cliffs: Prentice-Hall, 1960.

Weinstock, S. Resistance to extinction of a running response following partial reinforcement under widely spaced trials. J. comp. physiol. Psychol., 1954, 47, 318-322.

Note

1. The author is grateful to F. Dudley Klopfer and Keith A. Wollen who offered many helpful suggestions regarding the content of this article.

in different contexts several times by now, but the reader will be better served if we restrain ourselves from further speculations until these are presented with experimental evidence. However, one seemingly attractive hypothesis was that the slow instrumental change resulted because Group 400-20 maintained a higher licking rate throughout the post-shift phase than the control, Group 20-3. In certain response rate theories of reinforcement Group 400-20 might thus be considered to have a higher functional reinforcement magnitude. We regarded this hypothesis as improbable (but not impossible) for two reasons, insufficiently described in the report. At this time we are indebted to Allison for pointing to an analysis which further supports this contention.

1. If the differential consummatory rates were responsible for the differences in instrumental behavior we should require post-shift correlations higher than the .15 observed in Group 400-20. Although a theorist can find it profitable to deal with a correlative relationship as if it were a causative one, a correlation this low does not provide much hope for the future usefulness of speculation in that direction. The amount of variance accounted for on the last post-shift day by the preshift experimental treatment is irrelevant to this argument because the post-shift sequence could be arbi-

(Continuted on page 104) 